\title{
$\mathrm{BMC}$ \\ Plant Biology
}

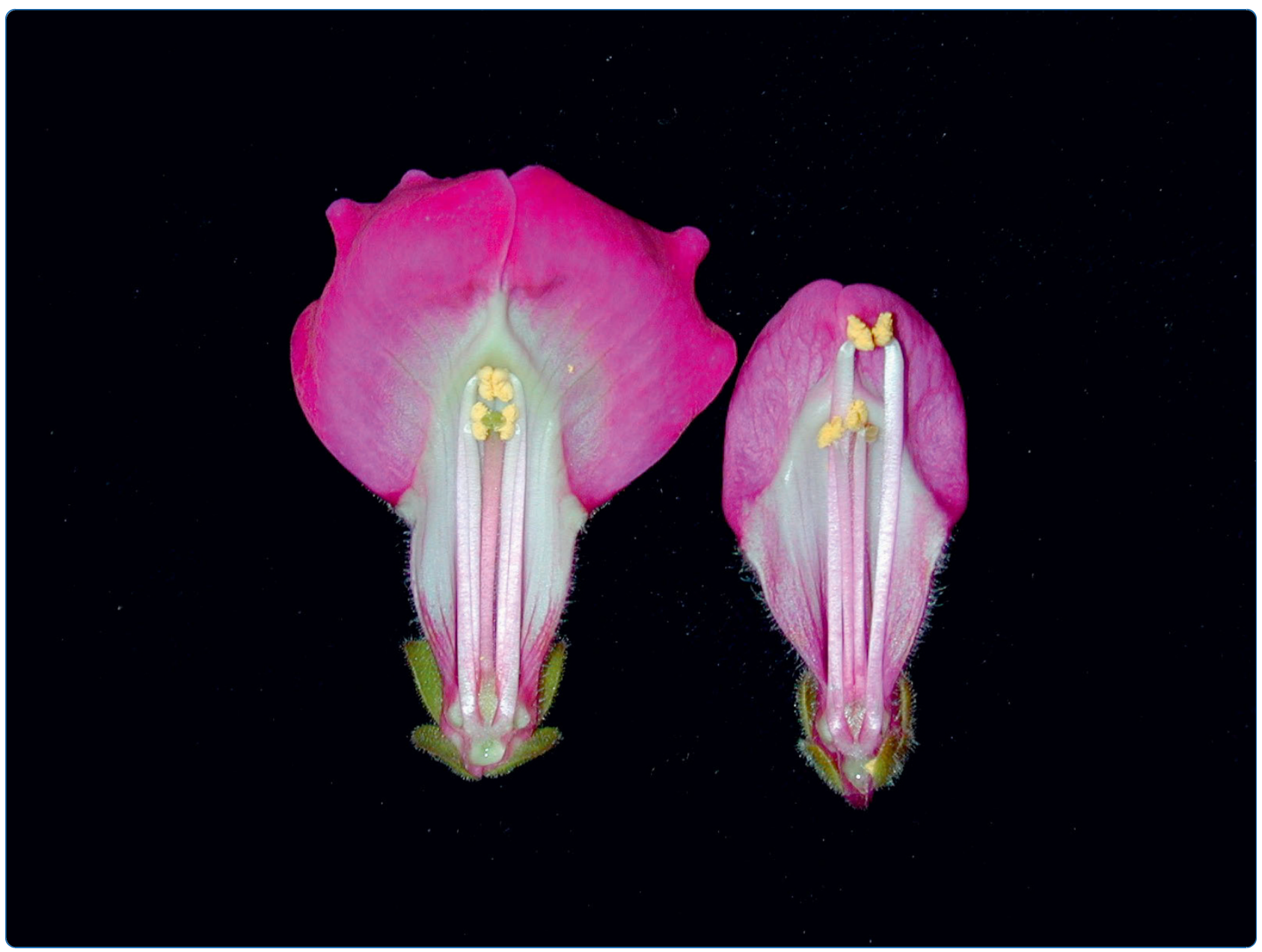

\section{A molecular recombination map of Antirrhinum}

majus

Schwarz-Sommer et al.

() Biomed Central 


\title{
A molecular recombination map of Antirrhinum majus
}

\author{
Zsuzsanna Schwarz-Sommer ${ }^{1}$, Thomas Gübitz ${ }^{2}$, Julia Weiss ${ }^{3}$, Perla Gómez-di-Marco ${ }^{3}$, Luciana Delgado-Benarroch ${ }^{4}$,
} Andrew Hudson ${ }^{5}$, Marcos Egea-Cortines ${ }^{3 *}$

\begin{abstract}
Background: Genetic recombination maps provide important frameworks for comparative genomics, identifying gene functions, assembling genome sequences and for breeding. The molecular recombination map currently available for the model eudicot Antirrhinum majus is the result of a cross with Antirrhinum molle, limiting its usefulness within A. majus.
\end{abstract}

Results: We created a molecular linkage map of A. majus based on segregation of markers in the F2 population of two inbred lab strains of $A$. majus. The resulting map consisted of over 300 markers in eight linkage groups, which could be aligned with a classical recombination map and the A. majus karyotype. The distribution of recombination frequencies and distorted transmission of parental alleles differed from those of a previous inter-species hybrid. The differences varied in magnitude and direction between chromosomes, suggesting that they had multiple causes. The map, which covered an estimated of $95 \%$ of the genome with an average interval of $2 \mathrm{cM}$, was used to analyze the distribution of a newly discovered family of MITE transposons and tested for its utility in positioning seven mutations that affect aspects of plant size.

Conclusions: The current map has an estimated interval of 1.28 Mb between markers. It shows a lower level of transmission ratio distortion and a longer length than the previous inter-species map, making it potentially more useful. The molecular recombination map further indicates that the IDLE MITE transposons are distributed throughout the genome and are relatively stable. The map proved effective in mapping classical morphological mutations of $A$. majus.

\section{Background}

Antirrhinum majus, the garden snapdragon, has been used as a model system for genetics since the early $20^{\text {th }}$ Century [1]. It is a member of a monophyletic group of about twenty five species that are native to the Mediterranean region share the same chromosome number $(2 \mathrm{n}=16)$ and are able to form fertile hybrids with each other [2]. The majority of species are allogamous, though cultivated $A$. majus lines and a few other wild species can self-fertilize.

A collection of $A$. majus mutants has been produced from some laboratory lines of $A$. majus selected for high transposon activity [3]. In several cases, these have been used to clone the corresponding genes by transposon

\footnotetext{
* Correspondence: marcos.egea@upct.es

${ }^{3}$ Institute of Plant Biotechnology (IBV), Technical University of Cartagena,

Campus Muralla del Mar, 30202 Cartagena, Spain

Full list of author information is available at the end of the article
}

tagging (e.g. [4-10]). In addition there is a collection of roughly four hundred classical mutants, mostly in an isogenic background (Sippe 50) [11,12]. The majority of these mutants does not show the genetic instability characteristic of transposon-induced mutations, and therefore have limited use for transposon tagging. The alternative approach of gene isolation by positional cloning is currently restricted by the availability of molecular recombination maps in Antirrhinum, though it has recently been successful in isolating the fistulata (fis) gene [13]. Though a classical fis mutation was genetically stable, it is caused by insertion of a miniature inverted-repeat transposable element (MITE), which is present in relatively low copy-number in all Antirrhinum species. Because the transposon family appeared relatively inactive it was called IDLE.

The existing molecular recombination map for Antirrhinum was built using the F2 of a cross between 
A. majus (line 165E) and a wild relative, A. molle [14]. The map identified eight linkage groups and use of common loci had allowed these to be related to a classical genetic map and to the A. majus chromosomes by in situ hybridization [15]. However, the majority of markers from the A. molle x A. majus hybrid showed significantly distorted transmission, which are likely to have affected the accuracy of the map, and the map also contained clusters of loci consistent with chromosome rearrangements between the species $[12,15]$. Such rearrangements were also suggested by observation of chromosomes [15]. These two factors would hinder attempts to map A. majus mutations in crosses to A. molle. A further disadvantage of using inter-species crosses to map A. majus mutations is that $A$. majus and A. molle differ in many morphological characters, including plant and organ size. Segregation of natural variation would therefore be likely to obscure the effects of mutations in hybrid mapping populations.

We therefore developed a linkage map of $A$. majus using the inbred lines Sippe50 and 165E. The map consists of 302 markers (protein coding sequences, AFLP and transposons), covering nearly $95 \%$ of the genome. As a proof of concept, we placed on the map six mutations affecting floral and overall size. We also mapped the distribution of $I D L E$ transposons, revealing that they are allocated with coding genes in all Antirrhinum chromosomes.

\section{Results \& discussion}

\section{Construction of a molecular linkage map for $A$. majus}

To construct a molecular linkage map for $A$. majus we crossed two inbred lines, 165E and Sippe 50. Line 165E originated from cultivated A. majus in the UK and is phenotypically distinct from Sippe 50, which was derived in Germany, possibly from a wild accession $[11,16]$. A single F1 progeny was self-pollinated to produce an F2 mapping population of 96 plants. This population therefore contains 192 recombinant copies of each chromosome, sufficient for mapping loci to a resolution of $\sim 1 \mathrm{cM}$. The F2 population was genotyped at 377 loci. These included 90 protein-coding genes, in which polymorphisms were detected by sequencing the alleles from both parents. The identities of the proteincoding genes are given in Table 1 . The remaining markers mainly comprised AFLP and insertions of the MITE transposon IDLE [13]. The genotype data were used to estimate a recombination map. Fifty-nine AFLP markers (28\% of the total) and one dominant IDLE insertion were present in significantly more or fewer F2 plants than expected and could either not be mapped or mapped only by reducing support for linkage groups significantly. These markers were therefore rejected. The remaining markers formed a map comprising
90 protein-coding genes, 87 of which were mapped as co-dominant CAPS or size polymorphisms, 159 dominant AFLP and 53 IDLE insertions (10 with co-dominant alleles and 43 dominant markers). A complete list of primers for each marker and the corresponding map position can be found in Additional file 1. At nine loci AFLP bands from both parents showed complete linkage in repulsion and were subsequently treated as synthetic co-dominant markers.

The resulting map comprised eight linkage groups with a total length of $562 \mathrm{cM}$ that was estimated to cover $95 \%$ of the genome (Figure 1). At this level of coverage, the average interval between markers was $2.0 \mathrm{cM}$, with $88 \%$ of the genome estimated to lie within $2.0 \mathrm{cM}$ of a marker and $99 \%$ within $5 \mathrm{cM}$. Although the average interval between co-dominant markers was $6.0 \mathrm{cM}$, a similar proportion of the genome $(83 \%)$ was within $2.0 \mathrm{cM}$ of the nearest co-dominant marker. Assuming a haploid genome size of $3.6 \times 10^{8}$ bp for A. majus [17], a marker interval of $2.0 \mathrm{cM}$ represents on average $1.28 \mathrm{Mbp}$ of DNA.

\section{Map comparison}

A previous molecular map for Antirrhinum had been produced from the F2 progeny of a cross between A. majus (line 165E) and the wild species A. molle [14]. To allow identification and alignment of linkage groups in the two populations, the genotypes from the previous mapping population were used to reconstruct a map using the same parameters as for the A. majus x A. majus F2. Markers common to both maps allowed identification of corresponding linkage groups and their orientations (Additional file 2).

The total A. majus map was about $54 \%$ larger than for A. majus x A. molle. However the variations in length differed in magnitude and direction between chromosomes (Figure 2). Two linkage groups (5 and 3) were slightly smaller in map A, while the remainders were significantly longer, suggesting that the causes of length differences varied between chromosomes.

Previous studies have reported both smaller and larger maps for intra-specific crosses as compared to inter-specific crosses $[18,19]$. Several factors might contribute to variations in map lengths for Antirrhinum and might differ between chromosomes. Of particular relevance to the utility of the A. majus map is the possibility that the two marker sets cover different parts of the genome. However, this seems unlikely, because although the two maps contain a different number of loci (296 in map A and 227 in map B) they are estimated to cover a similar proportion of the genome (95\% in A and 94\% in B using Method 4 [20].) Moreover, randomly removing 69 markers from A, to make the numbers of markers the same in both 
Table 1 List of EST-based markers and functional annotation

\begin{tabular}{|c|c|c|c|}
\hline Sequence number & EST annotation & Length in bp & min. eValue \\
\hline EM:AMA558924 & thioredoxin peroxidase & 723 & 1.0E-1.12106E-85 \\
\hline EM:AJ801757 & proline-rich apg-like protein & 670 & 1.0E-2.50815E-86 \\
\hline EM:AJ794773 & o-linked c-transferase & 758 & 1.0E-2.06855E-101 \\
\hline EM:AJ804794 & histone h1 & 556 & 1.0E-1.27731E-27 \\
\hline EM:AJ794598 & at4g20410-like protein & 736 & 1.0E-1.80515E-107 \\
\hline EM:AJ805499 & stearoyl-acyl carrier protein desaturase & 481 & 1.0E-9.70457E-56 \\
\hline EM:X57295 & TAP1 protein precursor & 5280 & 1.0E-1.98821E-44 \\
\hline EM:AY072736 & HIRZINA KNOX protein & 1462 & $1.0 \mathrm{E}-0.0$ \\
\hline EM:AJ802708 & Eukaryotic translation initiation factor 6 & 630 & 1.0E-1.16373E-87 \\
\hline EM:AJ794444 & mgc108135 protein & 675 & 1.0E-6.11236E-80 \\
\hline EM:AJ802293 & translational inhibitor protein & 589 & 1.0E-1.37912E-65 \\
\hline EM:AJ803243 & 60 s ribosomal protein 118 & 731 & 1.0E-2.80747E-92 \\
\hline EM:AJ559267 & heavy-metal-associated domain-containing protein & 504 & 1.0E-2.98463E-13 \\
\hline EM:AJ790658 & urease accessory protein $\mathrm{g}$ & 561 & 1.0E-3.52407E-97 \\
\hline EM:AJ792971 & gtp-binding protein & 628 & 1.0E-1.89892E-82 \\
\hline EM:AJ560201 & iron-sulfur cluster assembly protein & 768 & 1.0E-3.45238E-59 \\
\hline EM:AJ620906 & STYLOSA co-repressor & 2865 & $1.0 \mathrm{E}-0.0$ \\
\hline EM:AJ806659 & atp-dependent clp protease proteolytic subunit & 711 & 1.0E-1.54692E-116 \\
\hline EM:AJ560074 & leucine rich repeat protein & 754 & 1.0E-2.04947E-101 \\
\hline EM:AM422773 & YABBY4 transcription factor & 1395 & 1.0E-7.9976E-177 \\
\hline EM:X97639 & cyclin-dependent kinase, CDC2a & 1038 & 1.0E-2.78255E-170 \\
\hline EM:AJ806654 & $\mathrm{C} 2 \mathrm{H} 2$ zinc-finger protein & 530 & 1.0E-4.79832E-31 \\
\hline EM:AM422772 & YABBY2 transcription factor & 1373 & 1.0E-3.22687E-114 \\
\hline EM:AJ568130 & cyclic nucleotide-regulated ion channel & 620 & 1.0E-3.55048E-94 \\
\hline EM:AJ568031 & amino acid permease familyexpressed & 1459 & 1.0E-1.38642E-78 \\
\hline EM:AJ800340 & at3g04780 f7o18_27 & 721 & 1.0E-1.77924E-75 \\
\hline EM:AJ568062 & chloroplast translation initiation factor 2 & 415 & 1.0E-4.51282E-45 \\
\hline EM:S53900 & PLENA MADS-box transcription factor & 1073 & 1.0E-1.61386E-120 \\
\hline EM:AJ801384 & actin associated protein & 538 & 1.0E-5.43416E-33 \\
\hline EM:AJ800042 & multiple stress-responsive zinc-finger protein & 781 & 1.0E-1.45489E-60 \\
\hline EM:AJ805889 & centromere microtubule binding protein cbf5 & 692 & 1.0E-3.39584E-97 \\
\hline EM:AJ808934 & transcription factor & 884 & 1.0E-2.17962E-88 \\
\hline EM:AJ568063 & polygalacturonase-inhibiting protein & 734 & 1.0E-1.19729E-66 \\
\hline EM:AJ804237 & histidinol dehydrogenase & 634 & 1.0E-2.00488E-95 \\
\hline EM:AJ795662 & flavonoid 3-o-glucosyltransferase & 750 & 1.0E-9.60942E-83 \\
\hline EM:AJ800415 & erwinia induced protein 2 & 615 & 1.0E-2.67616E-49 \\
\hline EM:AJ796551 & Frigida & 666 & 1.0E-5.06947E-39 \\
\hline EM:AJ796122 & p-p-bond-hydrolysis-driven protein transmembrane transporter & 747 & 1.0E-3.07514E-73 \\
\hline EM:AJ800197 & atp-dependent protease clp atpase subunit & 594 & 1.0E-3.10775E-69 \\
\hline EM:AJ559052 & t-complex protein 1 epsilon tcp-1- & 690 & 1.0E-2.62699E-116 \\
\hline EM:AJ803361 & monodehydroascorbate reductase & 730 & 1.0E-7.35389E-109 \\
\hline EM:AJ802640 & isochorismatase hydrolase & 779 & 1.0E-1.51824E-94 \\
\hline EM:AY223518 & LIP1 apetala2-like transcription factor & 1845 & $1.0 \mathrm{E}-0.0$ \\
\hline EM:AJ805150 & photoassimilate-responsive protein par-like protein & 530 & 1.0E-7.5899E-61 \\
\hline EM:AJ620905 & STYLOSA1 co-repressor & 3123 & $1.0 \mathrm{E}-0.0$ \\
\hline EM:AJ801986 & at-rich element binding factor 3 & 590 & 1.0E-8.38628E-55 \\
\hline EM:X68831 & GLOBOSA MADS-box transcription factor & 6108 & 1.0E-5.69779E-27 \\
\hline EM:X76995 & polygalacturonase-inhibiting protein & 3545 & 1.0E-4.66003E-119 \\
\hline EM:AJ558819 & psap psi-p ptac8 tmp14 (thylakoid membrane phosphoprotein of $14 \mathrm{kda}$ ) dna binding & 762 & 1.0E-2.07028E-40 \\
\hline EM:AJ793550 & trna-methyltransferase subunit & 535 & 1.0E-7.89349E-61 \\
\hline EM:AJ620909 & SEUSS3A co-repressor & 3683 & $1.0 \mathrm{E}-0.0$ \\
\hline
\end{tabular}


Table 1 List of EST-based markers and functional annotation (Continued)

\begin{tabular}{|c|c|c|c|}
\hline EM:AJ800998 & Transcription factor lim & 710 & 1.0E-3.7918E-99 \\
\hline EM:AJ620910 & seu3b protein & 2004 & 1.0E-2.36396E-82 \\
\hline EM:AY451399 & CRABSCLAW-like YABBY transcription factor & 732 & 1.0E-1.78657E-70 \\
\hline EM:AJ794665 & nuclear cap binding protein subunit 2 & 673 & 1.0E-1.25817E-85 \\
\hline EM:AJ802365 & $-\mathrm{NA}-$ & 583 & 1.0E-1.68821E-23 \\
\hline EM:AJ801224 & $-\mathrm{NA}-$ & 613 & 1.0E-2.33555E-13 \\
\hline EM:AJ794216 & nuclear RNA binding & 758 & 1.0E-1.84607E-33 \\
\hline EM:AJ794472 & serine threonine protein kinase & 746 & 1.0E-1.35578E-75 \\
\hline EM:AJ568099 & pgr5-like a & 1478 & 1.0E-9.46041E-75 \\
\hline EM:AJ791655 & bzo2h3 (arabidopsis thaliana basic leucine zipper 63) dna binding transcription factor & 758 & 1.0E-9.80266E-27 \\
\hline EM:AJ790549 & immunophilin & 566 & 1.0E-1.28799E-54 \\
\hline EM:M55525 & FLORICAULA transcription factor & 1545 & $1.0 \mathrm{E}-0.0$ \\
\hline EM:AJ802861 & $-\mathrm{NA}-$ & 728 & 1.0E-1.22273E-47 \\
\hline EM:AJ799233 & delta-12 oleate desaturase & 736 & 1.0E-8.2567E-116 \\
\hline EM:AJ804300 & protein & 683 & 1.0E-6.22658E-88 \\
\hline EM:AJ803800 & af319475_1 alpha-expansin 9 precursor & 590 & 1.0E-5.56035E-91 \\
\hline EM:AJ803115 & protein & 654 & 1.0E-9.83593E-72 \\
\hline EM:AJ790136 & tfllb-related protein & 677 & 1.0E-1.59963E-96 \\
\hline EM:AJ805759 & eukaryotic translation initiation factor 6 & 689 & 1.0E-1.55443E-110 \\
\hline EM:AJ559280 & tic20-like protein & 710 & 1.0E-6.95853E-77 \\
\hline EM:AJ620907 & SEUSS1 protein & 3495 & $1.0 \mathrm{E}-0.0$ \\
\hline EM:AJ789733 & $-\mathrm{NA}-$ & 675 & 1.0E-6.54566E-74 \\
\hline EM:AJ800463 & tubulin alpha-6 chain & 605 & 1.0E-4.42202E-40 \\
\hline EM:AJ791186 & Glutaredoxin-like protein & 684 & 1.0E-1.57483E-30 \\
\hline EM:AJ790836 & b12 d protein & 564 & 1.0E-1.21222E-36 \\
\hline EM:AJ794452 & duf1230-containing protein & 763 & 1.0E-1.97117E-91 \\
\hline EM:AJ793362 & phosducin-like protein 3 & 578 & 1.0E-6.36625E-60 \\
\hline EM:Y16313 & CYCLOIDEA TCP transcription factor & 861 & 1.0E-1.34443E-129 \\
\hline EM:AY223519 & LIP2 apetala2-like transcription factor & 1914 & $1.0 \mathrm{E}-0.0$ \\
\hline EM:AJ800866 & polycomb protein ez1 & 507 & 1.0E-1.11628E-31 \\
\hline EM:AJ805209 & rer1a protein & 582 & 1.0E-1.72796E-60 \\
\hline EM:AJ568117 & phenylalanine ammonia-lyase & 619 & 1.0E-7.46548E-60 \\
\hline EM:AJ791765 & microtubule motor & 745 & 1.0E-7.82606E-45 \\
\hline EM:AJ808258 & flu (fluorescent in blue light) binding & 663 & 1.0E-2.25085E-39 \\
\hline EM:AJ793379 & rpm1-interacting protein 4 & 580 & 1.0E-1.07793E-22 \\
\hline
\end{tabular}

The ESTs were automatically annotated using BLAST2GO. The corresponding EST annotation was performed using a minimal threshold of e-6. Those genes with high homology to genes with unknown function were annotated as NA. Sequences with known mutant phenotypes in Antirrhinum are given their Antirrhinum gene names.

populations, reduced the length of map A by an average of only $2 \%$ (Additional file 3 ). Similarly maps made only with dominant protein-coding genes from each F2 population showed the same trends in map length differences (data not shown), suggesting that they are not dependent on the number or types of markers used.

The insensitivity of map length to the type of marker also suggests that the 51 mapped IDLE transposons were relatively stable, because excision of an IDLE in members of the mapping population would result in the wrong parental origin being assigned to its locus and an over-estimation of recombination frequencies. The relative stability of $I D L E$ markers was further supported by the finding that they were no more likely than other marker types to have an apparent recombination breakpoint immediately next to them, as would be expected if excision had resulted in an incorrect genotype.

Although many transposon families are predominant components of heterochromatin, MITE transposons have commonly been found associated with gene-rich regions $[21,22]$. This is consistent with the observed distribution of IDLE insertions in Antirrhinum, which are interspersed with protein-coding genes and do not appear to be clustered in centromeric or telomeric regions. 

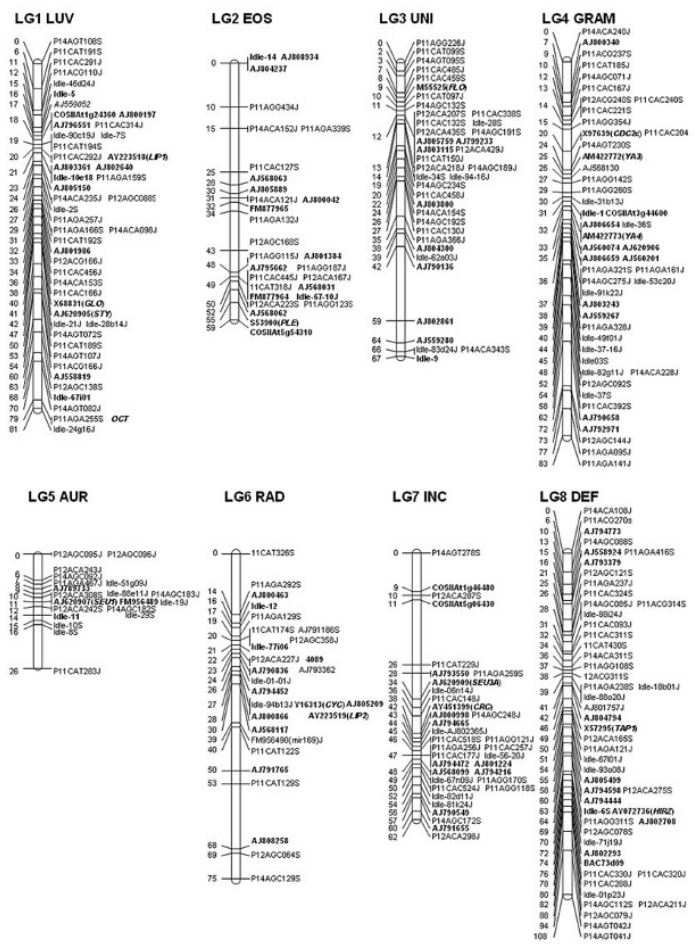

Figure $1 \mathrm{~A}$ molecular linkage map for Antirrhinum majus Sippe $50 \times 165 E$. The eight linkage groups are oriented, numbered and named as in previous Antirrhinum maps. Positions are given in centiMorgans (Kosambi). Protein-coding loci are named with their EMBL accession numbers as in Table 1 and with their Antirrhinum gene names in italics, where their functions are known from mutants. IDLE denotes a locus carrying an insertion of an IDLE transposon in one of the parents and loci with the suffix P are AFLP (see Materials \& Methods for AFLP nomenclature). Loci with codominant alleles are shown in bold and those with dominant alleles in regular type.

\section{Transmission ratio distortion differences between inter and intra-specific maps}

At least some of the length variation between maps might be attributed to transmission ratio distortion (TRD). This was more marked in the interspecies cross, in which loci representing most of the genome deviated significantly from their expected Mendelian ratios (Figure 3). It was most severe for LG6, in which A. molle carries a functional gametophytic self-incompatibility $(S)$ locus. This prevented recovery of F2 plants homozygous for A. molle alleles at LG6 unless recombination had occurred between the marker and the $S$ locus. In contrast, $A$. majus lacks a functional $S$ locus and shows only mildly distorted transmission of markers from LG6 (Figure 3). TRD can lead to under-estimation of map distances [23] and loss of marker information, for example no dominant markers closely linked to the A. molle $S$ allele were identified in map B. It can also lead to markers being wrongly assigned to linkage groups. The lower level of TRD in map A therefore justifies the use of mapping populations of $A$. majus rather than interspecies hybrids.

It was previously suggested that the clustering of markers in map B may be caused by chromosome inversions that distinguished $A$. majus from $A$. molle [14], preventing mapping of loci that lie within inversions. However, there is significant clustering $(\mathrm{p}<0.0001)$ of markers in both maps and significantly more clustering in map A than map B. Since fewer rearrangements are expected between two A. majus lines than between A. majus and A. molle clusters of markers appear unlikely to represent inversions.

\section{Map validation by mapping mutations affecting size}

One possible use of a molecular map is to determine the chromosomal positions of loci that have been identified by mutation. This can, for example, classify mutations that are potentially allelic, which is particularly useful for dominant mutations, and allows isolation of the affected genes on the basis of their positions. We therefore tested the utility of the A. majus map in determining the position of six classical mutations affecting aspects of plant size (Figure 4). All six mutations were in the Sippe 50 mutant background and therefore crossed to wild-type $165 \mathrm{E}$ to generate F2 mapping populations.

The nana (na) mutation described at the end of the XIXth century in the Vilmorin catalog [24], reduces plant size in a recessive fashion and flowers early irrespective of photoperiod. The na mutant phenotype

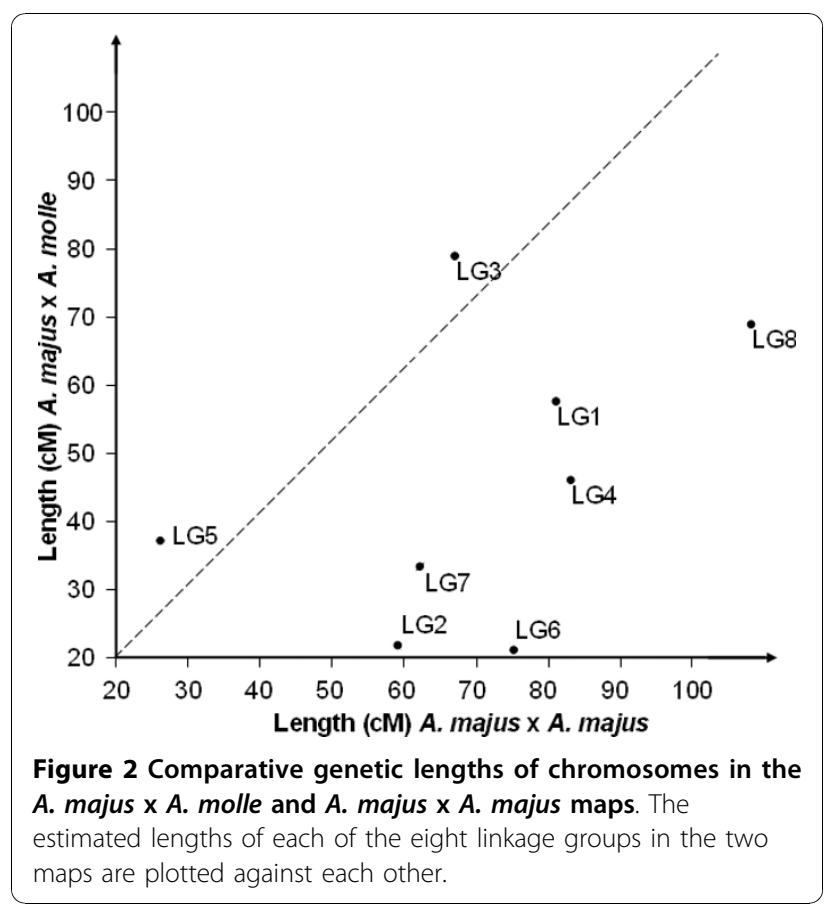




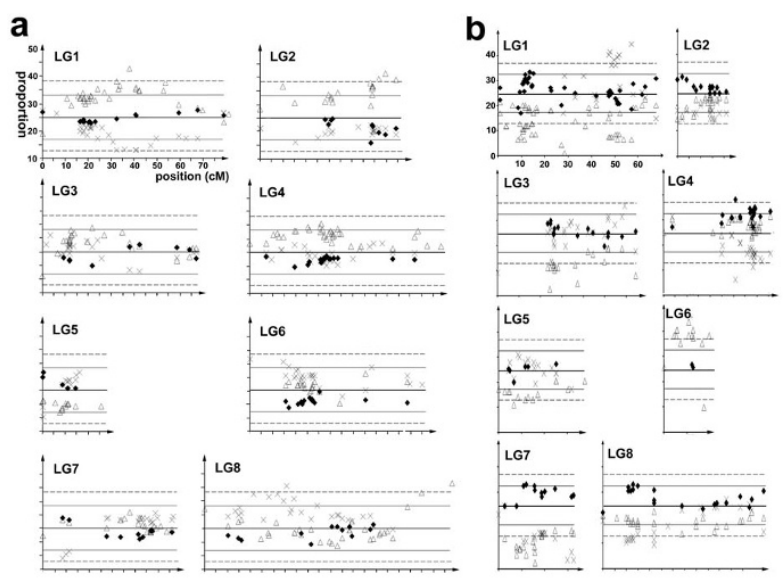

Figure 3 Transmission of parental alleles to $\mathbf{F} 2$ mapping populations. For the $A$. majus $\times A$. majus population (a) the proportion of Sippe 50 homozygotes (crosses), 165E homozygotes (triangles) and half the proportion of heterozygotes (diamonds) is plotted for each locus according to its position in the eight linkage groups (LG). The solid horizontal line represents the expected average proportion $(0.25)$ of each genotype class that is expected in the absence of distorted transmission. The solid and broken grey lines represent the approximate thresholds for significantly distorted genotype frequencies at the 0.95 and 0.99 levels, respectively. Genotype frequencies for the A. majus $\times$ A. molle population are shown in (b). The genotype frequencies and significance levels are represented as in a), except that crosses denote $A$. molle homozygotes.

segregated as expected for a recessive mutation in the F2 generation of the cross to 165E. However, a second allele nanalargiflora, which caused a somewhat weaker phenotype in the Sippe 50 genetic background [12], could not be distinguished from wild-type in F2 populations produced by crossing to $165 \mathrm{E}$ line. This highlights a potential problem arising from suppression of a weak mutant phenotype in a cross between two lines that differ, albeit slightly, in morphology. Another difficulty was identified in the case of the recessive muscoides (mus) mutation, which causes dwarfism. No mus mutants were initially identified in the F2 of the cross with 165E. However, mus mutants were recovered at a low frequency ( 2 out of 60 plants) when F2 seeds were germinated in Petri dishes, suggesting that the mus mutation can be lethal in the 165E genetic background.

The mutant hero affected stem thickness, a trait that seems to be partly controlled by genes affecting floral size in Arabidopsis like Bigbrother and Kluh [25,26]. However hero did not show a statistical difference from wild-type in lateral organ size, either in the original Sippe 50 background or in F2 populations, and segregated as expected of a recessive mutation in the F2 (data not shown).

Four mutations affecting floral size also segregated as expected in the F2 populations produced by crossing to $165 \mathrm{E}$ with compacta (co), compacta-ähnlich (coan) and formosa (fo) mutations appearing fully recessive, and Nitida ( $\mathrm{Ni})$ as semi-dominant [11]. In the case of $\mathrm{Ni}$ and $c o$ mutants, their phenotypes in the F2 were similar to those of the original background while coan, and $f_{0}$ mutants showed slightly larger differences from wildtype.

The mutants affect floral size in different ways, coan decreases flower size without affecting vegetative body size [27], while the co mutation reduces both flower and lateral organ size. The $f o$ mutation increases floral size, [28] while the $n a$ mutation reduces plant height and leaf width without significantly affecting flower size while the $N i$ mutation reduces the sizes of flowers, leaves and internodes in a dosage-dependent fashion.

As an initial approach, the mutations were mapped by bulk-segregant analysis [29]. DNA was extracted from several pools of four plants that shared the same phenotype and screened with a CAPS marker located in a middle region of each chromosome arm (a total of 16
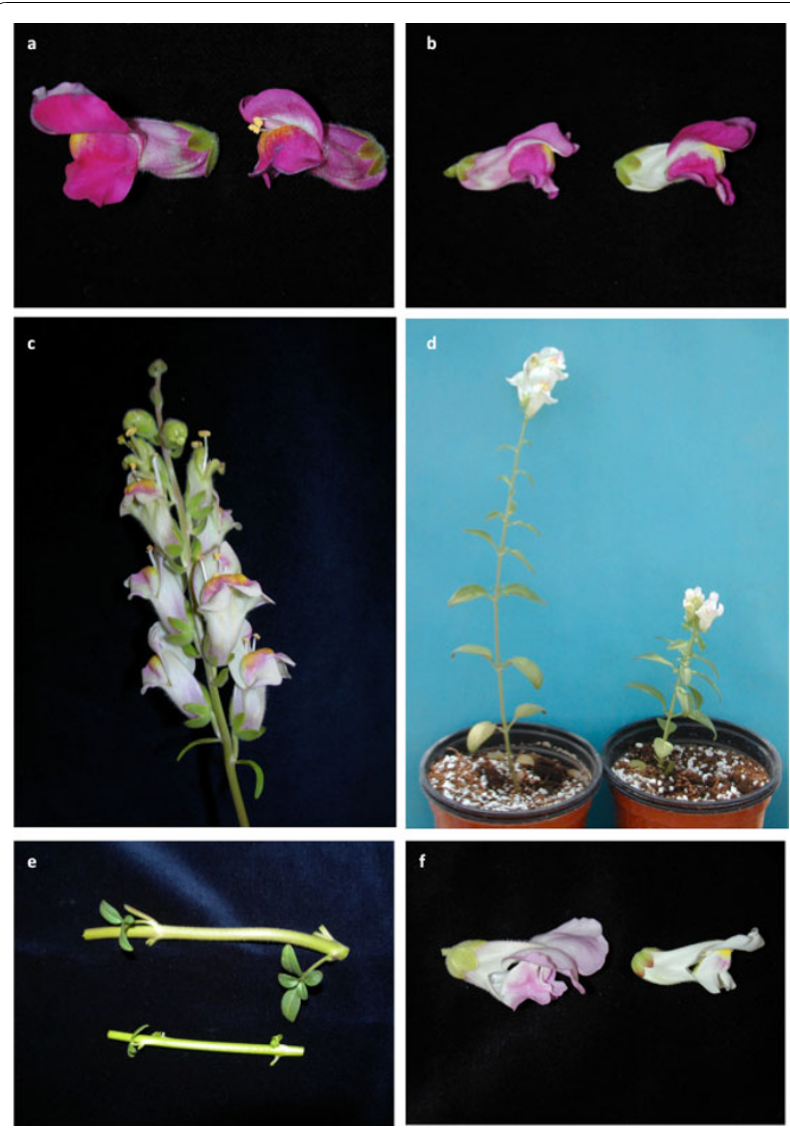

Figure 4 Phenotypic characteristics of the mutants used to validate the map. Phenotypes of compacta (a), formosa (b), compacta ähnlich (c) and nana (d), Pictures show wild type on the left and mutant on the right. The mutant heroina (e) above and wild type below. Stems of hero correspond to same internode in siblings. The mutant Nitida (f) wild type left, mutant right. 
Table 2 Map position of six mutants.

\begin{tabular}{lllcccc}
\hline Mutant & Closest Marker & LG & Marker position (cM) & Kosambi distance (cM) & n & significance \\
\hline coan & AJ790136 & LG3 & FLO & 0 & 43 & $*$ \\
co & AJ568117 & LG6 & 30 & 3.1 & 7.2 & 21 \\
Fo & SEU3A & LG7 & 34 & 4.6 & 22 & $*$ \\
hero & SEU3A & LG7 & 34 & 25.9 & 21 & $*$ \\
na & AJ568062 & LG2 & 52 & 9.1 & 50 & $*$ \\
Ni & PLE (S53900) & LG2 & 55 & & $*$ \\
\hline
\end{tabular}

Mutants were originally obtained in the Sippe 50 background and mapped by crossing with $165 \mathrm{E}$. Markers were considered significantly linked for $\chi^{2}$ tests of $\mathrm{p}<0.05$

markers). Markers that $\chi^{2}$ tests suggested were not linked to the size mutation were rejected. Where evidence for linkage was found, additional CAPS markers from the same chromosome regions were used to analyze individual F2 plants to refine map positions. Statistically significant linkage was found between the additional markers and the mutations in all cases (Table 2). The distance between a mutation and the closet marker ranged from the coan locus and the marker AJ790136 in LG3, which showed no recombination in 43 homozygous mutants, to $n a$ and AJ568062 in LG2 which were separated by about $26 \mathrm{cM}$.

We have therefore shown that it is feasible to map mutations in crosses between these two Antirrhinum lines, even mutations with relatively subtle effects on plant size. Extending this approach to map based cloning should become more feasible as the density of molecular markers in Antirrhinum increases. However, the ability to map with even moderate resolution can be used to identify potentially allelic mutations, including natural variants. One of the major features of Antirrhinum species is that they differ widely from each other in size. Several genes underlying this size variation have been mapped as quantitative trait loci (QTL), e.g. [30]. Like the size mutants analyzed here, the QTL can affect a single type of organ or have more pleiotropic effects. It should now be possible to identify whether any classical size mutations might correspond to size QTL on the basis of map positions and so select candidate mutations for more allelism tests. A corresponding classical mutation can facilitate QTL isolation and the understanding of QTL gene function.

\section{Conclusions}

We have constructed a molecular linkage map using two inbred lines of Antirrhinum majus, 165E and Sippe 50. The newly developed map has eight linkage groups and a total length of $562 \mathrm{cM}$ with an estimated coverage of $95 \%$ of the genome. There is an average interval of $2 \mathrm{cM}$ between codominant markers in $88 \%$ of cases and $5 \mathrm{cM}$ in $99 \%$, and assuming a genome size of $3.6 \times 10^{8}$ $\mathrm{bp}$, an interval of $2 \mathrm{cM}$ represents on average $1.28 \mathrm{Mbp}$ of DNA.
The new map is $54 \%$ longer than the previously published map of A.majus x A. molle, and this difference is caused by increased length of the different linkage groups, except 3 and 5 that were slightly shorter indicating that map length differences were the result of differences between chromosomes in the two crosses.

We have mapped 51 IDLE transposons that are interspersed with EST-based markers indicating that MITE transposons, like in other plants, are found in gene-rich regions. Determination of EST-based markers will allow future use of the A.majus map for comparative genomic studies with other plants.

The new map has fewer regions of TRD reinforcing its usefulness to determine genome positions with higher accuracy. This has been achieved by validating the map with six classic mutants affecting floral size ( $N i, \mathrm{co}$, coah and $f o$ ), body size (Hero and $n a$ ) and flowering time $(n a)$. We have been able to obtain map positions for each mutant using F2 mapping populations.

\section{Methods}

\section{Plant material}

Seeds of Antirrhinum majus L. were germinated and grown as described by [31].

The A. majus line Sippe 50 [11] was obtained originally from the IPK Gatersleben and maintained by self-pollination while the second wild-type line $165 \mathrm{E}$ was produced by several generations of self-pollination from line JI.98 [16,32]. An F2 population $(n=$ 96) for mapping molecular markers was selected at random from the progeny of a single $\mathrm{F} 1$ hybrid of Sippe $50 \times 165 \mathrm{E}$. The mutants compacta (co) [33], compacta ähnlich (coan) [12], formosa (fo), Grandiflora (Graf), heroina (Hero), Nitida (Ni) [11] and nana (na) [24] were obtained from the IPK Gatersleben collection. All the mutants are in the Sippe 50 genetic background. Mutations were mapped in F2 populations produced by crossing mutants to the $165 \mathrm{E}$ wild-type.

DNA was extracted using a NucleoSpin ${ }^{\circ}$ kit (Macherey-Nagel) from $100 \mathrm{mg}$ of frozen leaf samples that had been ground to a powder in liquid $\mathrm{N}_{2}$. 


\section{Mapping transcribed genes}

Sequence tagged sites (STS) were generated using primers able to amplify regions from a collection of $A$. majus EST sequences that showed differences between Sippe50 and 165E [34]. The identities of PCR products were confirmed by sequencing. For six genes, both parental alleles could be distinguished by differences in the sizes of their amplified products in agarose gels without digestion. A further three loci amplified from only one parent and were therefore treated as dominant markers. For the remaining genes, restriction site polymorphisms were identified by comparing sequences of amplified products and the loci scored as co-dominant CAPS resolved in agarose gels. The ESTs used to develop markers were annotated automatically using the BLAST2GO program $[35,36]$.

\section{AFLP analysis}

AFLP were amplified from DNA that had been digested with PstI and MseI using eight combinations of selective primers. Primers for the PstI ends of fragments had 3' selective di-nucleotides AA (P11), AC (P12) or AT (P14) and were labeled with one of four different fluorescent dyes (6-FAM, VIC, NED or PET) while those at the MseI ends had 3' extensions of ACA, AGC, AGT, CAC or CAT. Products were separated with the LIZ-500 internal size standard (ABI) using an ABI 3730 DNA Analyzer. Output files were converted to fsa format using the program obtained from http://dna.biotech. wisc.edu/ABRF/3730toGSconverter.exe, processed using Genescan software (ABI) and the presence or absence of bands scored from virtual gels created using a version of the program Genographer http://hordeum.oscs.montana. edu/genographer/ that had been modified by its authors to accommodate the five different color channels. AFLPs were scored as dominant markers. They were named according to the primers used to generate them, their size and their parent of origin - e.g. locus 11AGA141J amplified with selective primers P11 and Mse-AGA as a band of $141 \mathrm{nt}$ and originated from parent $165 \mathrm{E}$

\section{Mapping MITE transposons}

Different copies of the IDLE transposon were identified by homology to the insertion in the fistulata- 2 mutation in $A$. majus [13] either by hybridization to genomic clones or comparison to A. majus BAC clones. The host sequences to both sides of $10 I D L E$ insertions were identified. In these cases, primers from the two flanking regions were used to distinguish the presence or absence of the transposon on the basis of size polymorphism allowing these loci to be scored as co-dominant markers. For 43 insertions only one flanking sequence was obtained and a flanking primer was used with an $I D L E$ primer to detect the presence of an insertion, which was treated as a dominant marker.

\section{Map construction}

To construct the molecular recombination map for the F2 population, co-dominant markers were scored as one of three allelic states (homozygous 165E, homozygous Sippe 50 or heterozygous) while dominant markers were assigned to one or other parent and scored for the presence or absence in F2 individuals. A map was estimated from the genotype data at 377 loci using Joinmap 3.0 [37], using a minimum LOD score of 6.0 to identify potential linkage groups. Maps of each linkage group were then established using the default thresholds for elimination of markers and establishing marker order and the Kosambi mapping function [38] to calculate genetic distances. Transmission ratio distortion was represented for loci with co-dominant alleles by plotting the frequencies of each homozygote and half the frequency of heterozygotes and for dominant loci by the frequency of homozygotes lacking the dominant allele. Each class was expected with a frequency of 0.25 and significant deviations from this expectation were assessed with $\chi^{2}$ tests.

Total genome size was estimated using Method 4 from [20] or by adding twice the average marker spacing to each chromosome, with both methods providing very similar estimates. The percentage of the genome within a particular map distance of the nearest molecular marker was estimated with the method used by [39]. To analyze whether markers showed non-random clustering, the number of $1 \mathrm{cM}$ intervals expected to contain a particular number of markers was calculated from the total number of markers and map length, assuming that the markers were distributed randomly (i.e. that the number of markers per $1 \mathrm{cM}$ interval followed a Poisson distribution). This null hypothesis was tested against the observed frequency distribution of markers, using a $\chi^{2}$ test. The frequency distributions of marker densities for the two maps were also compared directly, using a $\chi^{2}$ test.

\section{Mutant mapping}

To map mutations, F2 plants were selected for genotyping on the basis of their phenotype. Four pools, each containing a similar amount of DNA from four homozygous plants, were first used to scan for linkage to one of 16 markers-representing both arms of all eight chromosomes. Linkage to a marker locus was suggested by an enrichment of one of its parental alleles in more than one of the pools (i.e. enrichment of the Sippe 50 allele in pools of recessive mutations or the $165 \mathrm{E}$ allele in wild-type pools in the case of dominant mutants). Suspected linkage was investigated further by genotyping 
between 20 and $60 \mathrm{~F} 2$ individuals for the original locus and at additional loci linked to it. Linkage was assessed using $\chi^{2}$ tests to identify significant deviations from random segregation in the mutant population and the Kosambi function used to estimate map distances between mutations and markers from recombination frequencies.

\section{Additional material}

Additional file 1: Map positions, primers and restriction enzymes
used to detect IDLE transposons and EST-based markers.
Additional file 2: Anchoring of linkage groups in map B (on the
left) to those of the newly created map A (right).
Additional file 3: The effects of marker number on the length of
map A. Map B contained 69 fewer markers than map A. To
investigate whether a larger number of markers was responsible for the
longer length of map A, 69 markers were removed at random and map
A recalculated. This was repeated 1,000 times with removal of a different
set of randomly selected markers each time. The frequency distribution
of total map lengths obtained in the simulations is shown. The average
length was 552 cM, a reduction of only $2 \%$ from the map estimated with
all markers. Therefore a larger number of markers does not account for
map A being $54 \%$ longer than map B

List of abbreviations

AFLP: Amplified fragment length polymorphism; CM: centiMorgan; Co: Compacta; Coan Compacta ähnlich; Fo: Formosa; Hero: Heroina; MITE: Miniature Inverted Repeat Transposable element; Na: Nana; Ni: Nitida; TRD: transmission ratio distortion

\section{Acknowledgements}

This work is dedicated to the memory of Zsuzsanna Schwarz-Sommer. We would like to express our deepest sorrow for the loss of Zsuzsanna-SchwarzSommer while this work was under way. Work in the lab of MEC was supported by grant AGL2007-61384 and Bananasai (BioCARM). Work in the lab of $\mathrm{AH}$ was supported by the BBSRC.

\section{Author details \\ 'Max-Planck-Institut für Züchtungsforschung, Carl-von-Linné-Weg 10, 50829 Köln, Germany. ${ }^{2}$ Deutsche Forschungsgemeinschaft (DFG)-Wissenschaftliche Geräte und Informationstechnik, D-53170 Bonn, Germany. ${ }^{3}$ Institute of Plant Biotechnology (IBV), Technical University of Cartagena, Campus Muralla del Mar, 30202 Cartagena, Spain. Instituto de Botánica del Nordeste (IBONE)- CONICET-Facultad de Ciencias. Agrarias, Universidad Nacional del Nordeste (UNNE) CC 209, Corrientes 3400 Argentina. ${ }^{5}$ Institute of Molecular Plant Sciences, University of Edinbugh," King's Buildings, Mayfield Rd., Edinburgh EH9 3JH, UK.}

\section{Authors' contributions}

ZsSS, TG, AH and MEC designed experiments. ZsSS developed the EST and IDLE markers, TG and AH did the AFLP markers, TG, ZsSS and AH made the map. MEC did the bioinformatic analysis of EST annotation. PGC, LDG and JW mapped the mutants. PGC, LDG, JW and MEC grew the F2 populations and scored the phenotypes. MEC did the mutant pictures. LDG, JW and MEC did the phenotypic analysis of the mutants. AW and MEC wrote the draft and all the authors except ZsSS read, corrected and approved it.

Received: 18 February 2010 Accepted: 15 December 2010 Published: 15 December 2010

\section{References}

1. Schwarz-Sommer Z, Davies B, Hudson A: An everlasting pioneer: the story of Antirrhinum research. Nature Reviews Genetics 2003, 4(8):657-666.
2. Vargas $P$, Carrió E, Guzmán B, Amat E, Güemes J: A geographical pattern of Antirrhinum (Scrophulariaceae) speciation since the Pliocene based on plastid and nuclear DNA polymorphisms. Journal of Biogeography 2009, 36(7):1297-1312.

3. Carpenter R, Coen ES: Floral Homeotic Mutations Produced by Transposon-Mutagenesis in Antirrhinum-Majus. Genes and Dev 1990, 4(9):1483-1493.

4. Bonas U, Sommer H, Saedler H: The 17-kb Tam1 element of Antirrhinum majus induces a 3-bp duplication upon integration into the chalcone synthase gene. EMBO J 1984, 3(5):1015-1019.

5. Martin C, Carpenter R, Sommer H, Saedler H, Coen ES: Molecular analysis of instability in flower pigmentation of Antirrhinum majus, following isolation of the pallida locus bt transposon tagging. EMBO J 1985, 4(7):1625-1630.

6. Bradley D, Carpenter R, Sommer H, Hartley N, Coen E: Complementary floral homeotic phenotypes result from opposite orientations of a transposon at the plena locus of Antirrhinum. Cell 1993, 72(1):85-95.

7. Waites $R$, Selvadurai HR, Oliver IR, Hudson A: The PHANTASTICA gene encodes a MYB transcription factor involved in growth and dorsoventrality of lateral organs in Antirrhinum. Cell 1998, 93(5):779-789.

8. Luo D, Carpenter R, Vincent C, Copsey L, Coen E: Origin of floral asymmetry in Antirrhinum. Nature 1996, 383(6603):794-799.

9. Hudson A, Carpenter R, Doyle S, Coen ES: Olive: a key gene required for chlorophyll biosynthesis in Antirrhinum majus. EMBO J 1993, 12(10):3711-3719.

10. Noda K, Glover BJ, Linstead P, Martin C: Flower colour intensity depends on specialized cell shape controlled by a Myb-related transcription factor. Nature 1994, 369(6482):661-664.

11. Stubbe H: Genetik und Zytologie von Antirrhinum L. sect. Antirrhinum. Jena: Veb Gustav Fischer Verlag; 1966

12. Stubbe H: New mutants of Antirrhinum majus. Kultupflanze 1974, 22:189-213.

13. Cartolano M, Castillo R, Efremova N, Kuckenberg M, Zethof J, Gerats T, Schwarz-Sommer Z, Vandenbussche M: A conserved microRNA module exerts homeotic control over Petunia hybrida and Antirrhinum majus floral organ identity. Nature Genetics 2007, 39:901-905.

14. Schwarz-Sommer Z, Silva ED, Berndtgen R, Lonnig WE, Muller A, Nindl I, Stuber K, Wunder J, Saedler H, Gubitz T, et al: A linkage map of an F-2 hybrid population of Antirrhinum majus and A-molle. Genetics 2003, 163(2):699-710.

15. Zhang DF, Yang QY, Bao WD, Zhang Y, Han B, Xue YB, Cheng ZK: Molecular cytogenetic characterization of the Antirrhinum majus genome. Genetics 2005, 169(1):325-335.

16. Harrison BJ, Carpenter R: Resurgence of Genetic Instability in AntirrhinumMajus. Mutat Res 1979, 63(1):47-66.

17. Bennett MD, Bhandol P, Leitch IJ: Nuclear DNA Amounts in Angiosperms and their Modern Uses-807 New Estimates. Ann Bot 2000, 86(4):859-909.

18. Hall MC, Willis JH: Transmission ratio distortion in intraspecific hybrids of Mimulus guttatus: implications for genomic divergence. Genetics 2005, 170(1):375-386.

19. Albrecht $E$, Chetelat RT: Comparative genetic linkage map of Solanum sect. Juglandifolia: evidence of chromosomal rearrangements and overall synteny with the tomatoes and related nightshades. Theor Appl Genet 2009, 118(5):831-847.

20. Chakravarti A, Lasher LK, Reefer JE: A maximum likelihood method for estimating genome length using genetic linkage data. Genetics 1991, 128(1):175-182.

21. Initiative IB: Genome sequencing and analysis of the model grass Brachypodium distachyon. Nature 2010, 463(7282):763-768.

22. Zhang Q, Arbuckle J, Wessler SR: Recent, extensive, and preferential insertion of members of the miniature inverted-repeat transposable element family Heartbreaker into genic regions of maize. Proc Natl Acad Sci USA 2000, 97(3):1160-1165.

23. Liu B-H: Statistical genomics. Cleveland/Boca Ratón, Fl.: CRC Press; 1998.

24. Vilmorin : Vilmorin's, Blumengärtnerei. Bd.1 Antirrhinum majus, S.756. Berlin: Paul Parey; 18961.

25. Anastasiou E, Kenz S, Gerstung M, MacLean D, Timmer J, Fleck C, Lenhard M: Control of Plant Organ Size by KLUH/CYP78A5-Dependent Intercellular Signaling. Dev Cell 2007, 13:843-856. 
26. Disch S, Anastasiou E, Sharma VK, Laux T, Fletcher JC, Lenhard M: The E3 ubiquitin ligase BIG BROTHER controls Arabidopsis organ size in a dosage-dependent manner. Curr Biol 2006, 16(3):272-279.

27. Delgado-Benarroch L, Weiss J, Egea-Cortines M: The mutants compacta ahnlich, Nitida and Grandiflora define developmental compartments and a compensation mechanism in floral development in Antirrhinum majus. J Plant Res 2009, 122:559-569.

28. Delgado-Benarroch L, Causier B, Weiss J, Egea-Cortines M: FORMOSA controls cell division and expansion during floral development in Antirrhinum majus. Planta 2009, 229:1219-1229.

29. Michelmore RW, Paran I, Kesseli RV: Identification of markers linked to disease-resistance genes by bulked segregant analysis: a rapid method to detect markers in specific genomic regions by using segregating populations. Proc Natl Acad Sci USA 1991, 88(21):9828-9832.

30. Feng X, Wilson Y, Bowers J, Kennaway R, Bangham A, Hannah A, Coen E, Hudson A: Evolution of Allometry in Antirrhinum. Plant Cell 2009, 21(10):2999-3007.

31. Bayo-Canha A, Delgado-Benarroch L, Weiss J, Egea-Cortines M: Artificial decrease of leaf area affects inflorescence quality but not floral size in Antirrhinum majus. Sci Hort 2007, 113:383-386.

32. Sommer H, Saedler H: Structure of the Chalcone Synthase Gene of Antirrhinum-Majus. Molecular \& General Genetics 1986, 202(3):429-434.

33. Kuckuck H, Schick R: Die Erbfaktoren bei Antirrhinum majus und ihre Bezeichnung. Zf Induck Abst-u Vererbungs/ 1930, 56:51-83.

34. Bey M, Stuber K, Fellenberg K, Schwarz-Sommera Z, Sommer H, Saedler $H$, Zachgo S: Characterization of Antirrhinum petal development and identification of target genes of the class B MADS box gene DEFICIENS. Plant Cell 2004, 16(12):3197-3215.

35. Gotz S, Garcia-Gomez JM, Terol J, Williams TD, Nagaraj SH, Nueda MJ, Robles M, Talon M, Dopazo J, Conesa A: High-throughput functional annotation and data mining with the Blast2GO suite. Nucl Acids Res 2008, 36(10):3420-3435.

36. Conesa A, Gotz S, Garcia-Gomez JM, Terol J, Talon M, Robles M: Blast2GO: a universal tool for annotation, visualization and analysis in functional genomics research. Bioinformatics 2005, 21(18):3674-3676.

37. Van Ooijen JW, Voorrips RE: JoinMap ${ }^{\circledR}$ 3.0, Software for the calculation of genetic linkage maps. Wageningen, the Netherlands: Plant Research International; 2001.

38. Kosambi DD: The estimation of map distances from recombination values. Ann Eugen 1944, 12:172-175.

39. Fishman L, Kelly AJ, Morgan E, Willis JH: A genetic map in the Mimulus guttatus species complex reveals transmission ratio distortion due to heterospecific interactions. Genetics 2001, 159(4):1701-1716.

doi:10.1186/1471-2229-10-275

Cite this article as: Schwarz-Sommer et al:: A molecular recombination map of Antirrhinum majus. BMC Plant Biology 2010 10:275.

\section{Submit your next manuscript to BioMed Central and take full advantage of:}

- Convenient online submission

- Thorough peer review

- No space constraints or color figure charges

- Immediate publication on acceptance

- Inclusion in PubMed, CAS, Scopus and Google Scholar

- Research which is freely available for redistribution

Submit your manuscript at www.biomedcentral.com/submit
Biomed Central 